\title{
Development of Novel Connections for Pre-cast Composite and Pre-cast Concrete Frames
}

\author{
J.D Nzabonimpa ${ }^{1}$, Won-Kee Hong ${ }^{1}$, Seon-Chee Park ${ }^{1}$, Sunkuk Kim ${ }^{1}$ \\ ${ }^{1}$ Department of Architectural Engineering, Kyung Hee University, \\ Yongin 446-701, Republic of Korea \\ *Corresponding author's e-mail: hongwk@khu.ac.kr
}

\begin{abstract}
In some applications, the conventional steel pipe racks were encased with concrete to protect the frame from fire. However, the concrete encasing steel is not considered to contribute to structural capacity at all. This paper proposed pipe rack frames encased by precast concrete, but with functions both as a part of structural elements contributing to flexural load bearing capacity and to fire proofing. The new steel-concrete composite structural system consisting of steel, concrete with reinforcements, extended steel plates with bolts designed based on inelastic finite element method provides efficient structural performances, reducing material quantities with the protection from fires. Additionally extended plate with bolts introduced for column-beam joint assembly played important roles in providing moment connections. AISC 358 introduced the use of extended plate similar to the proposed connection. Significant experimental and analytical investigations were performed to verify structural behaviour of the composite frame. Material quantities were also compared to demonstrate economy of the new frames compared with conventional pipe rack frames.
\end{abstract}

\section{KEYWORDS}

Pipe rack, Composite, Precast, Extended end plate, Moment connection, AISC 358, Inelastic analysis, Strain compatibility

\section{INTRODUCTION}

Figures 1(a) and 1(b) show conventional pipe rack frame without concrete cover. Braces were required to provide lateral stiffness to the pinned pipe rack frame. Concrete cover in conventional pipe rack depicted in Figure 2(a) was only used as the protection for fireproofing, not used as load resisting structural element because no proper reinforcements were placed to interact with concrete cover. As a result, the conventional concrete encasing steel members serves as only fire proof in most pipe rack applications. Figures 2(a) and 2(b) viewed identically are both pipe rack frames encased by concrete but with different structural performances of concrete. In pipe rack shown in Figure 2(b), reinforcements are placed in the concrete to provide load resisting structural capacity. 

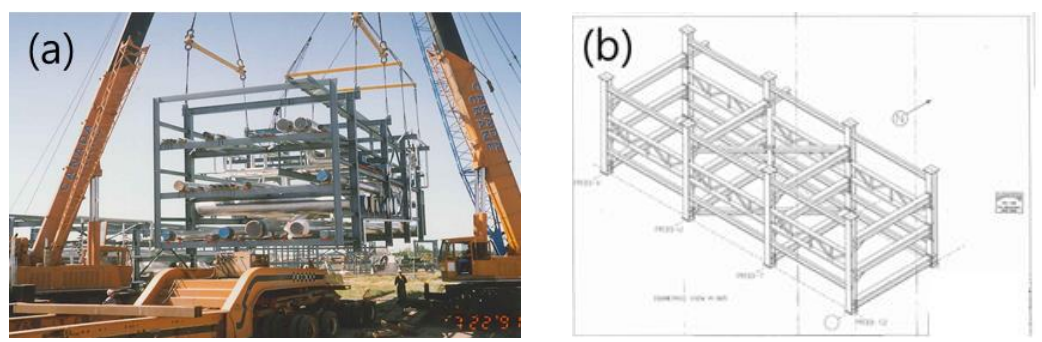

Figure 1. Conventional steel pipe rack without concrete cover
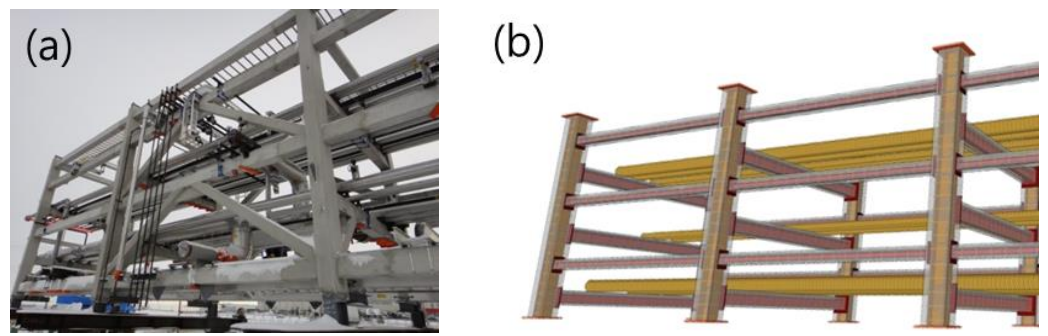

Figure 2. Conventional and Composite steel pipe rack with concrete cover

\section{RESEARCH METHODS}

\section{Experimental and Analytical investigation}

In the proposed pipe rack frame system, the column and beam was bolt-jointed eliminating concrete works which were inevitable for conventional column-beam joints using concrete. The bolts joints are designed to provide rigid moment connections, preventing lateral braces required for the conventional pinned steel frame. It was shown that these joint bolts could be disassembled quickly and easily to cooperate with sudden design changes that may occur at any construction phase. The new joint system consists of steel end plates at beams and plates on the face of columns which are bolted together to transfer moment between joints as shown in Figure 3. These structural members were designed based on inelastic strain compatibility. Specially the end plate with proper thickness should be designed to be able to transfer tensile forces from beams reinforcements to reinforcing bars that are anchored in columns to make joints rigid moment joints. The extensive inelastic analysis was performed for calculating lifted deformation of end plates for both conservative and economic design.

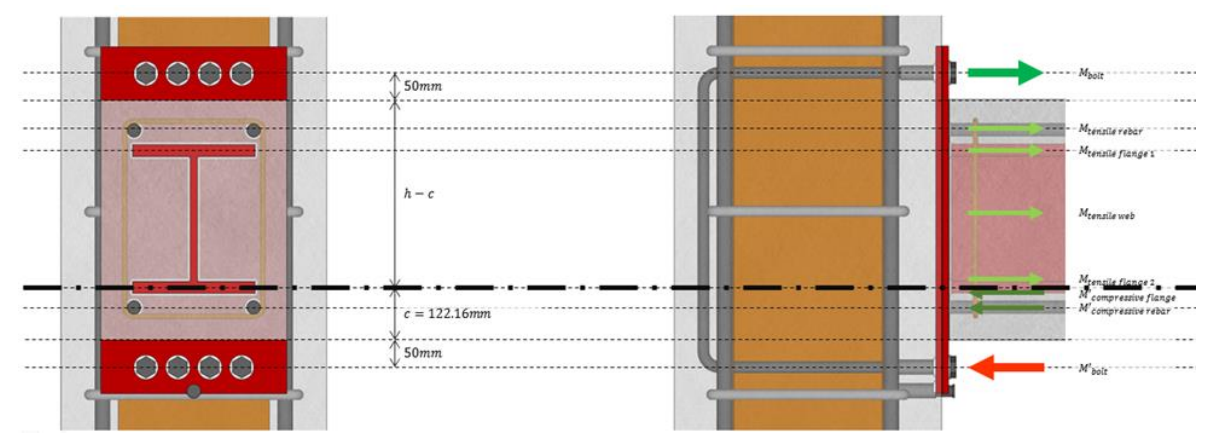

Figure 3. The new joint system 
Figure 4 shows set-up for experiment for the proposed beam and column. Lateral loading was applied to the specimen as shown in Figure 5. The beam end plates with 16 and $20 \mathrm{~mm}$ thickness were deformed regardless the filler types as shown Table 1. These end plates were unable to transfer tensile forces from beams to columns. However, it was proved that the beam end plates with $45 \mathrm{~mm}$ thickness transferred tension forces from beam to column, making the joint rigid moment connection as shown in Specimen B2. Similar performances were observed for columns. The column with connection plate of $45 \mathrm{~mm}$ thickness transferred tension forces from the upper column to lower column. . Figures 6 and 7 demonstrate load-displacement relationships for Specimens B2 and C2. This connection can be used to connect columns for modular constructions.

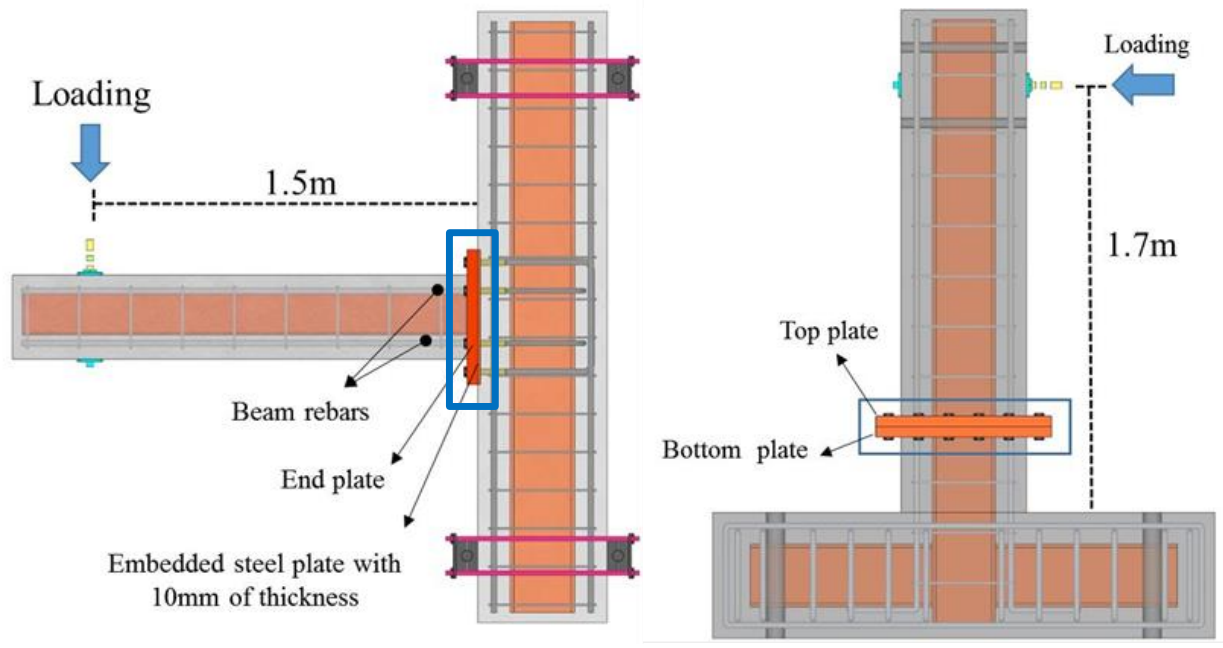

Figure 4. Beam and Column for Experimental Investigation,
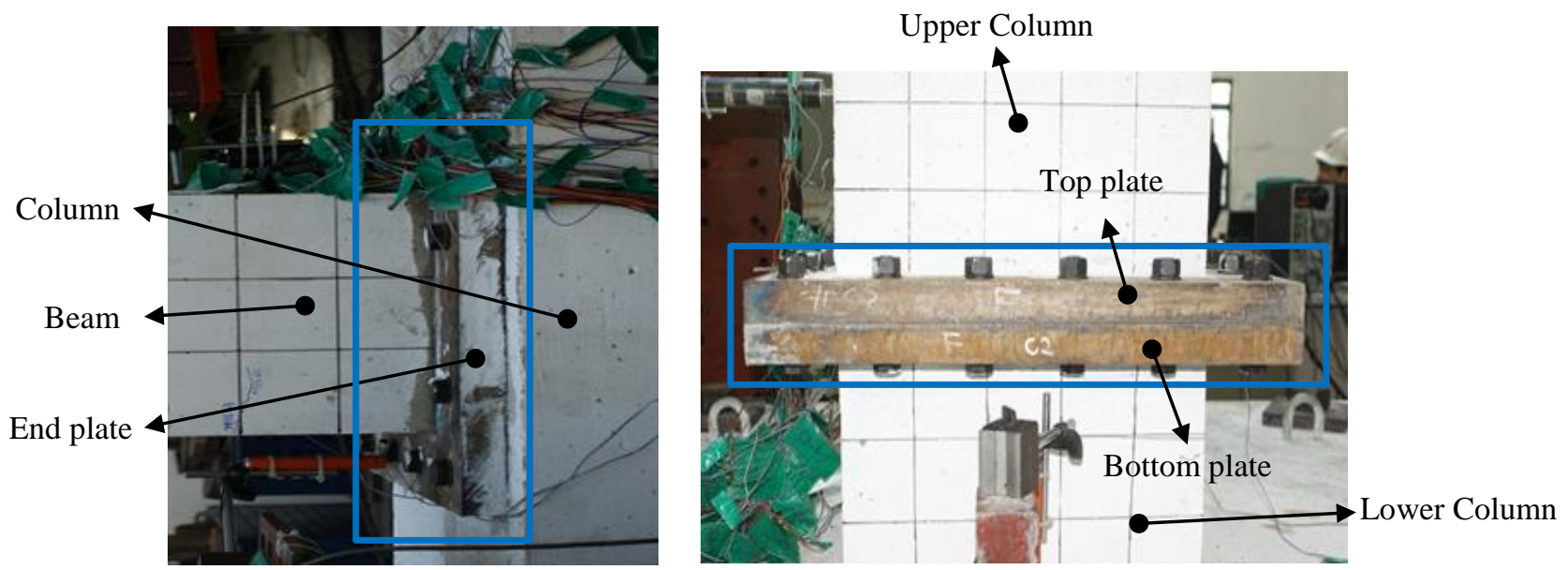

Figure 5. Application of lateral loading (Beam, Column) 
Table 1. Specimen Summary

\begin{tabular}{|c|c|c|}
\hline \multicolumn{2}{|c|}{ Specimen(Plate thickness) } & Deformation \\
\hline B1(20mm) & Welded rebar & $\begin{array}{l}\text { No deformation } \\
\text { (premature failure at rebar welding) }\end{array}$ \\
\hline B2(45mm) & Embedded nut & No deformation \\
\hline B3(20mm) & Filler Concrete & $10 \sim 14 \mathrm{~mm}$ \\
\hline B4(16mm) & Filler Concrete & $15 \mathrm{~mm}$ \\
\hline B5(20mm) & Filler plate & $14 \mathrm{~mm}$ \\
\hline B6 & Control specimen & - \\
\hline $\begin{array}{c}\text { C1(two } 20 \mathrm{~mm} \text { plates } \\
=>30.8, \text { combined } \\
\text { thickness })\end{array}$ & Welded rebar & $\begin{array}{l}\text { No deformation } \\
\text { (premature failure at rebar welding) }\end{array}$ \\
\hline $\mathrm{C} 2(45 \mathrm{~mm})$ & Embedded nut & No deformation \\
\hline $\begin{array}{c}\text { C3(two } 20 \mathrm{~mm} \text { plates } \\
\text { => 30.8, combined } \\
\text { thickness })\end{array}$ & Filler Concrete & $8 \mathrm{~mm}$ (Top plate), $8 \mathrm{~mm}$ (Bottom plate) \\
\hline $\begin{array}{c}\text { C4(two } 16 \mathrm{~mm} \text { plates } \\
\text { => } 25.8, \text { combined } \\
\text { thickness })\end{array}$ & Filler Concrete & $11 \mathrm{~mm}$ (Top plate), $11 \mathrm{~mm}$ (Bottom plate) \\
\hline $\begin{array}{c}\text { C5 }(\text { two } 20 \mathrm{~mm} \text { plates } \\
\text { => 30.8, combined } \\
\text { thickness })\end{array}$ & Filler plate & $13 \mathrm{~mm}$ (Top plate), $5 \mathrm{~mm}$ (Bottom plate) \\
\hline C6 & Control specimen & - \\
\hline
\end{tabular}

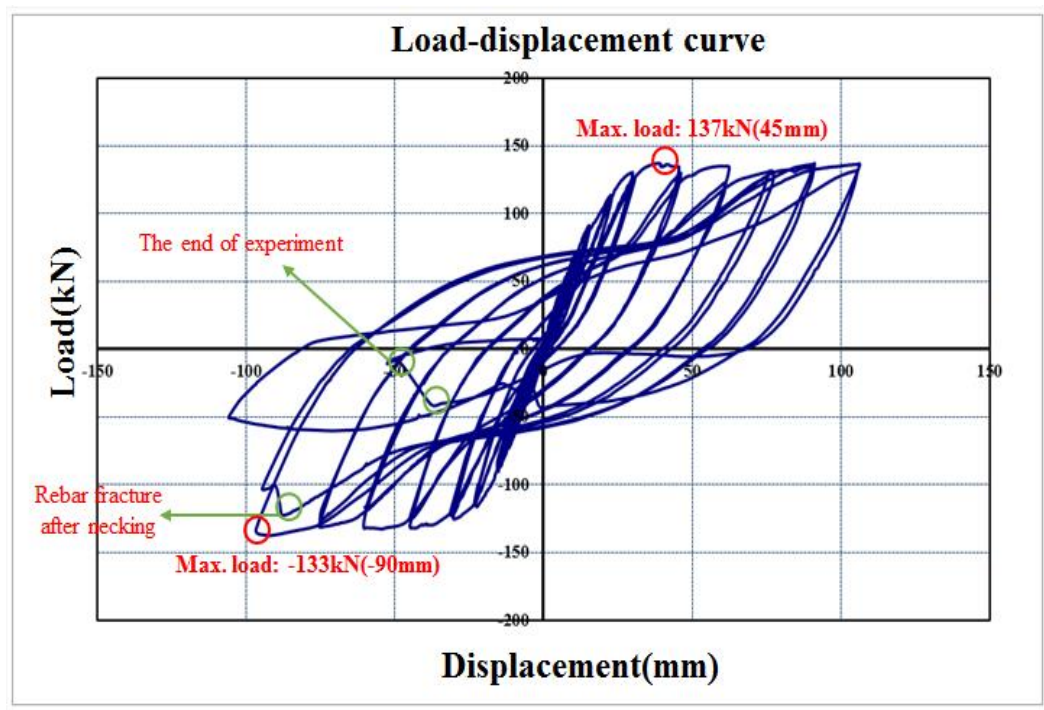

Figure 6. Load-Displacement relationships for B2 specimen 


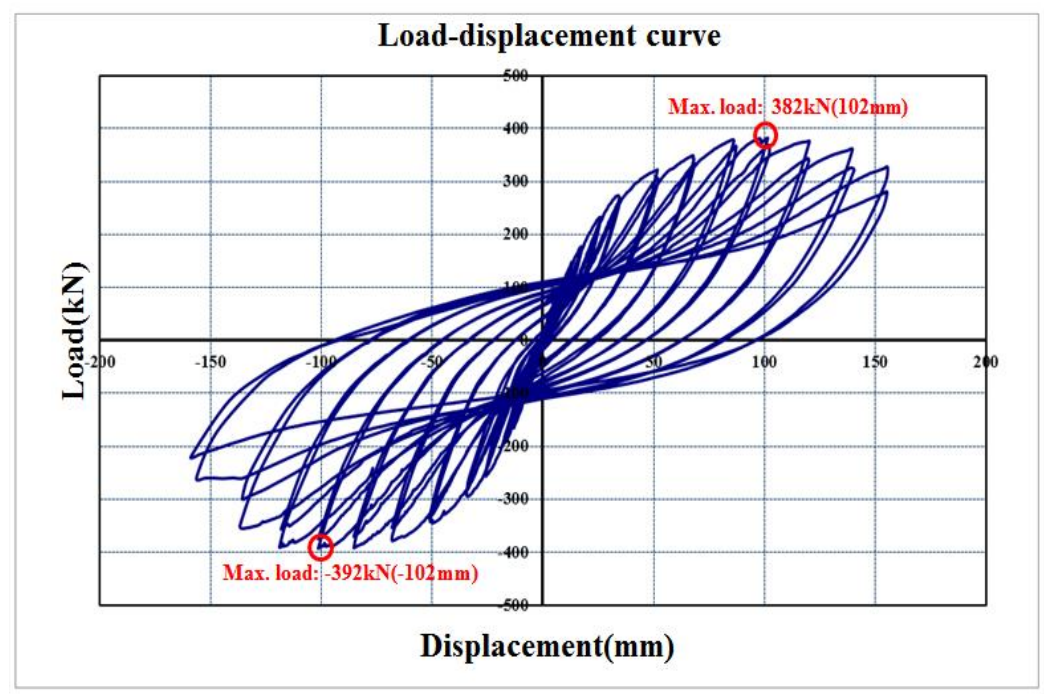

Figure 7. Load-Displacement relationships for $\mathrm{C} 2$ specimen

Figure 8 compares the test data with analytical calculations for control beam(B6). The analytical prediction based on strain compatibility was well correlated with the test data less than $4 \%$ error. As can be seen in the Figure 8, the analytical investigation showed that the concrete started to spall at concrete strain of 0.0042 . The specimen lost $40 \%$ of its concrete strength when maximum usable concrete strain of 0.0054 was used as shown in figure 8 . It is recommended that conventional steel concrete composite beams be designed up to the maximum usable concrete strain 0.004 .

\section{Beam : Displacement \& strain vs. load curve}

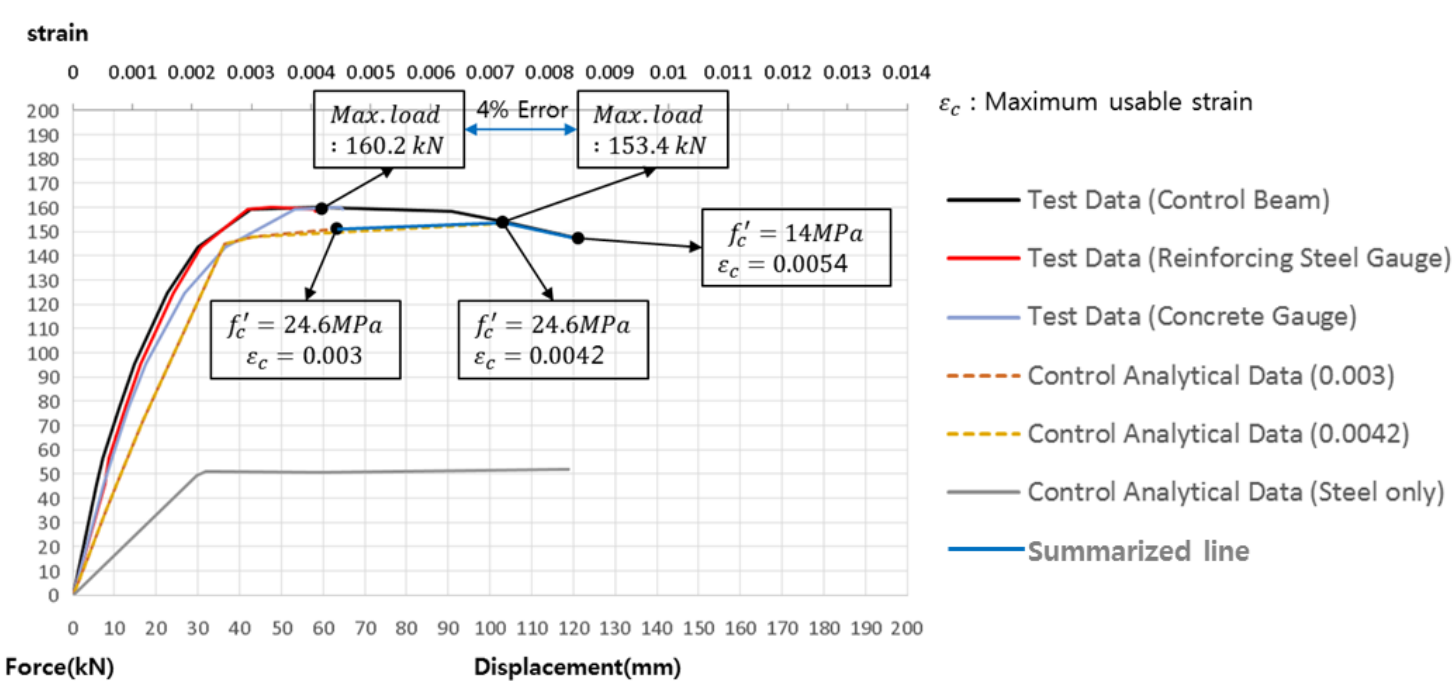

Figure 8. Comparison between test data and analytical data For B6 
Figure 9 compares the structural behaviour of control beam (B6) to the beam (B2) with extended plate proposed in this study. The B6 control beam was a composite frame with conventional beam-column joint while B2 beam was an identical composite frame but with joint assembled with extended end plate and bolts. The difference in structural performance observed by test data indicated by Arrow \#2 shown in figure 9 was due to the size differences of reinforcing steels used in the specimens B6 and B2, indicating the joint proposed in this study demonstrated similar structural performance with conventional beam-column joint. Diameters of $25 \mathrm{~mm}$ and $20 \mathrm{~mm}$ were used for B6 and B2, respectively. The similar difference in structural performance was demonstrated by the control analytical investigation as shown by Arrow \#1. The control analytical data was the calculated value obtained for the conventional joint connection. These two similar differences by Arrows \#1 and \#2 verified that joint connection with end plate(Specimen B2) performed similarly to conventional joint connection. The control analytical values were compared well with test data with $45 \mathrm{~mm}$ thick plate, proving that the proposed connections with beam end plate performed as moment connections. The $45 \mathrm{~mm}(325 \mathrm{Mpa})$ thick extended plate for Specimen B2 demonstrated stiffness enough to resist tensile forces from reinforcing steels of the beam during bending. The Arrow \#3 in Figure 9 indicated strength reduction of moment resisting capacity in Specimen \#4 which was assembled with beam end plate of $16 \mathrm{~mm}$. During the test, extensive damage with uplift deformation of the $16 \mathrm{~mm}$ plate was observed due to the tension force from beam re-bars. This type of structural deformation was not found with Specimen \#2 with which end plate of $45 \mathrm{~mm}$ was installed.

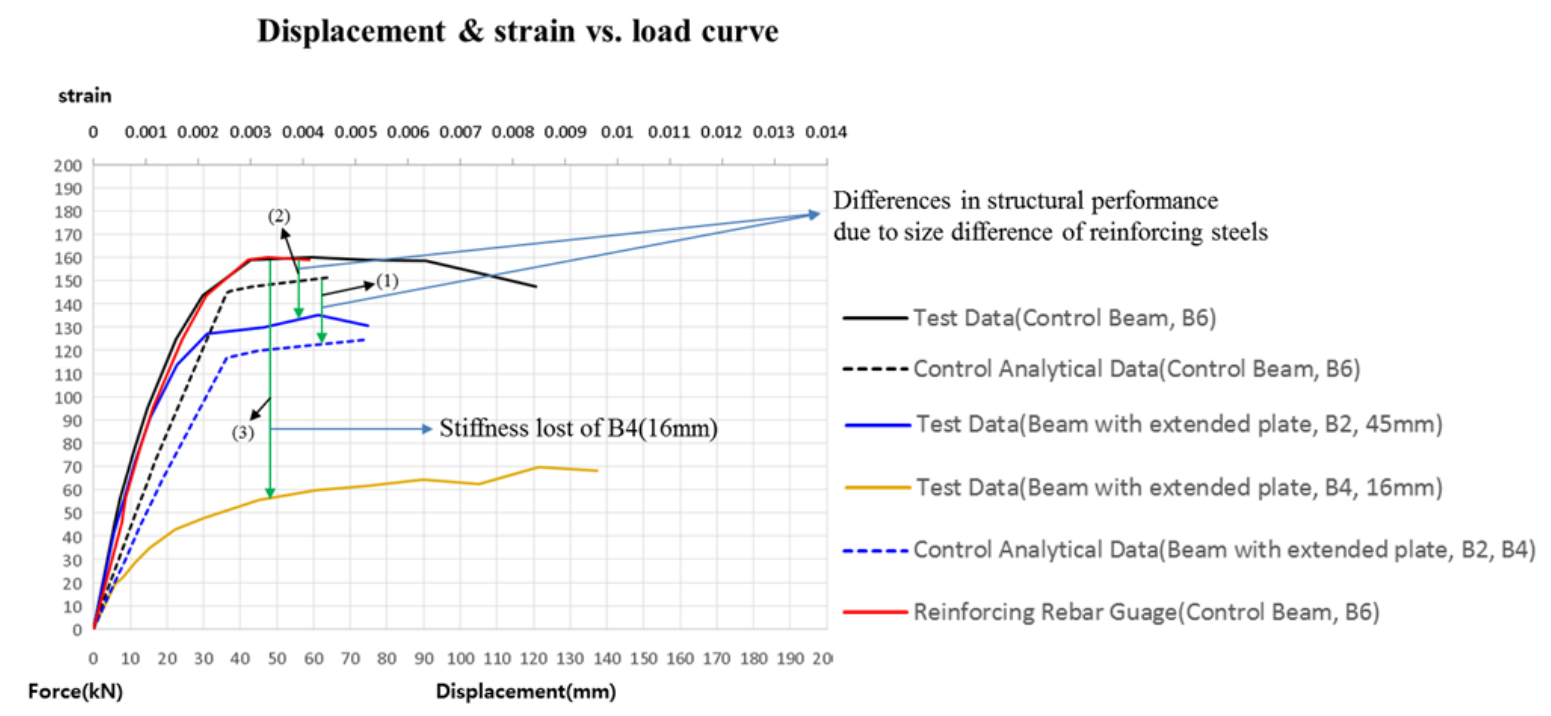

Figure 9. Control beam (B6) vs. Beam (B2) with extended plate

Plate thickness of $25 \mathrm{~mm}$ to resist tension force of $851 \mathrm{kN}$ from beam was determined by inelastic finite element method with the inelastic deformation of $1.4 \mathrm{~mm}$ at the location where tension force was applying, as shown in Figure 10. The steel plate with high yield strength of 650Mpa was used in the analysis while thickness of $45 \mathrm{~mm}$ with the yield strength of 325Mpa was required to provide stiffness to transfer moment at joint as shown in Specimen B2. 

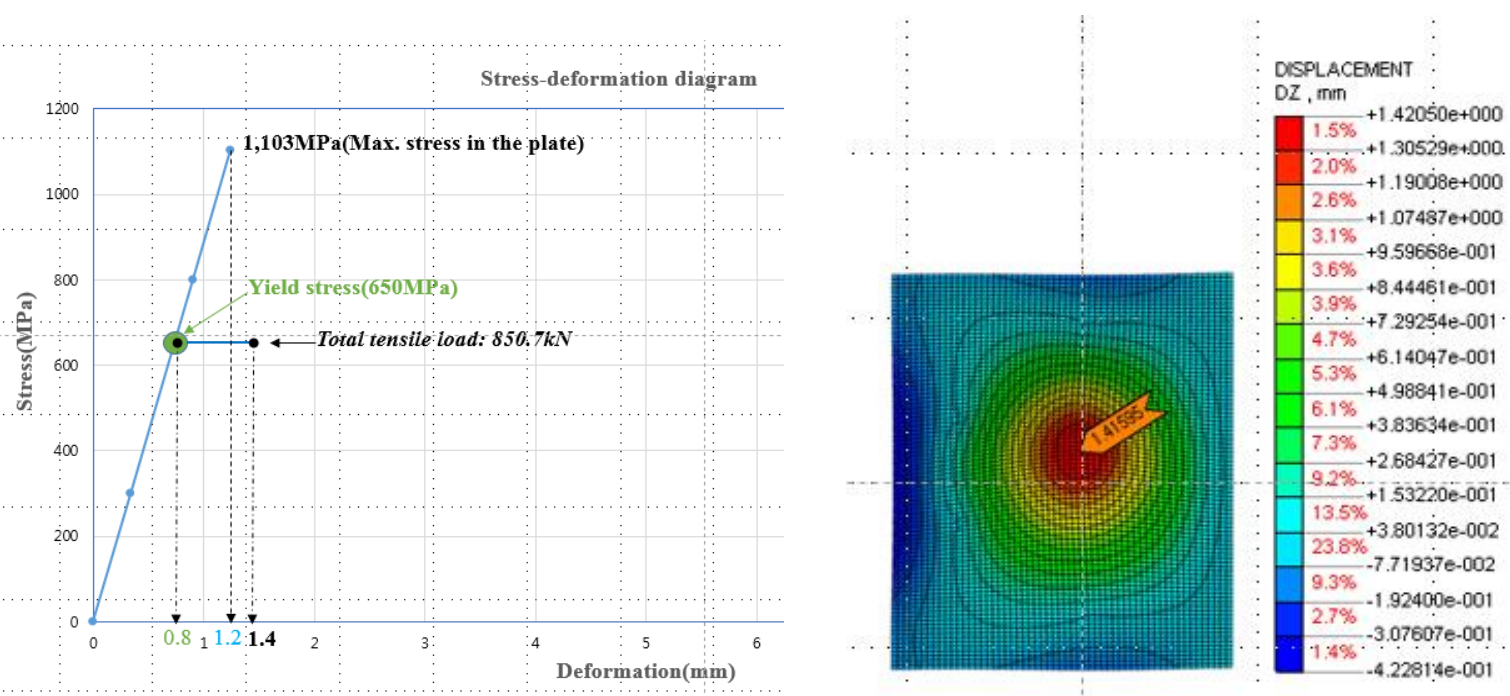

Figure 10. Inelastic finite analysis of beam end plate

Figure 11 shows joints of precast frame with extended beam end plate and embedded column plate that were assembled by bolts. The application of the moment resisting joint for precast frame can provide fast assembly as steel frame, enhancing constructability and structural integrity as well. These precast frames with simplified connections can be implemented into pipe racks and buildings as well.
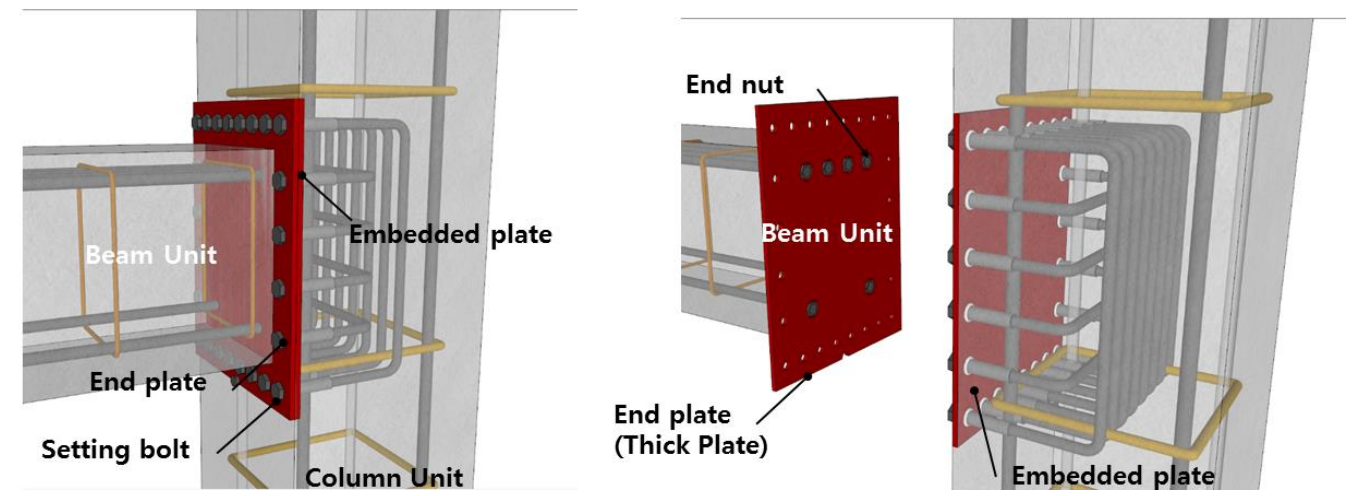

Figure 11. Precast frame joint with end plate and bolts

\section{RESULTS AND DISCUSSION}

Table 2 compares the material quantity of composite frames vs. conventional steel pipe rack. In this table it was assumed that the conventional steel pipe rack was encased by concrete for fireproofing. Significant material savings were found when structural contributions from concrete were considered with conventional steel pipe racks as proposed introduced in this paper.

Table 2. Reduction of Material Quantity of Composite Frame(this paper) vs. 
Frame(Pipe rack frame with fire proof)

\begin{tabular}{|c|c|c|c|c|c|c|}
\hline \multicolumn{7}{|c|}{ Pipe Rack Frame with Fire Proof [Total] } \\
\hline \multicolumn{2}{|c|}{ Components } & $\begin{array}{l}\text { Smart Frame } \\
\text { (H shaped steel) }\end{array}$ & $\begin{array}{l}\text { Smart Frame } \\
\text { (T shaped steel) }\end{array}$ & \begin{tabular}{|c|} 
Smart Frame \\
(End H shaped \\
steel)
\end{tabular} & $\begin{array}{c}\text { Smart Frame } \\
\text { (End T shaped } \\
\text { steel) }\end{array}$ & $\begin{array}{c}\text { Conventional } \\
\text { Steel Pipe } \\
\text { Rack }\end{array}$ \\
\hline \multicolumn{2}{|c|}{ Concrete $\left(\mathrm{m}^{3}\right)$} & 21.1 & 21.1 & 21.1 & 21.1 & 49.2 \\
\hline \multicolumn{2}{|c|}{ Rebar (kg) } & $2,026.2$ & $2,531.6$ & $2,159.4$ & $2,119.6$ & 0.0 \\
\hline \multicolumn{2}{|c|}{ Steel $(\mathbf{k g})$} & $8,998.1$ & $8,062.1$ & $7,477.1$ & $7,504.1$ & $40,348.3$ \\
\hline \multicolumn{2}{|c|}{ Rebar+Steel (kg) } & $11,024.2$ & $10,593.7$ & $9,636.4$ & $9,623.6$ & $40,348.3$ \\
\hline \multirow{4}{*}{$\begin{array}{c}\text { Comparison } \\
\text { with } \\
\text { Conventional } \\
\text { Steel Pipe } \\
\text { Rrack }\end{array}$} & Concrete & \multicolumn{4}{|c|}{$57.2 \%$ Reduction } & \\
\hline & Rebar & & \\
\hline & Steel & 77.7\% Reduction & $\begin{array}{c}\mathbf{8 0 . 0 \%} \\
\text { Reduction }\end{array}$ & $\begin{array}{c}\mathbf{8 1 . 5 \%} \\
\text { Reduction }\end{array}$ & $\begin{array}{c}\mathbf{8 1 . 5 \%} \\
\text { Reduction }\end{array}$ & \\
\hline & Rebar+Steel & 72.7\% Reduction & $\begin{array}{c}73.7 \% \\
\text { Reduction }\end{array}$ & $\begin{array}{c}\mathbf{7 6 . 1 \%} \\
\text { Reduction }\end{array}$ & $\begin{array}{c}76.1 \% \\
\text { Reduction }\end{array}$ & \\
\hline
\end{tabular}

\section{CONCLUSIONS}

The extensive and experimental analytical investigation carried out to confirm the structural behaviour of the proposed pipe rack with end plates in this study demonstrated appropriate strength to support pipe loadings that conventional pipe racks were supporting. It was uncovered that the stiffness of steel end plate beams was one of very critical elements to transfer tensile force from beams to columns. It was also found that the bolts connecting the two steel plates of the beams and columns should be carefully designed to transfer loading. The steel-concrete composite pipe rack with proposed end plates designed based on conventional pipe rack loading condition was compared with conventional steel pipe rack. It was concluded that steel-concrete composite frames for the pipe rack introduced in this paper were capable of providing both a structural capacity and fire proofing protection, resulting in a significant reduction of the amount of steel up to $75 \%$ of steel tonnage. It was also suggested to remove joint concrete works as required in conventional fireproofing using concrete.

\section{ACKNOWLEDGEMENTS}

This work was supported by the Technology Transfer Center for National R\&D Program(TTC) grant funded by the Korea government(MSIP)(No. 2014K000239).

\section{REFERENCES}

AISC (2005). AISC 358-05, Prequalified Connections for Special and Intermediate Steel Moment Frames for Seismic Applications, American Institute of Steel Construction, Chicago, IL

Ali Reza Keyvani Boroujeni (2013). "Linear and nonlinear analysis for seismic design of piping system" Journal of Civil Engineering and Construction Technology, vol. 4(4), pp. 149156

Richard M. D. (2010). “Design of Structural Steel Pipe Racks” AISC Engineering Journal 